\title{
Editorial
}

\section{Special Issue on Nano Photonics}

\section{Zeev Zalevsky}

School of Engineering, Bar-Ilan University, Ramat-Gan 52900, Israel

The fields of nano and biophotonics as well as the field of micro electronics became very much related to each other both in straight forward industrially related applications as well as part of joint scientific activity. The main interface between those three fields is in the attempt to incorporate

*Address correspondence to this author at the School of Engineering, BarIlan University, Ramat-Gan 52900, Israel; Tel: 972-3-5317055; Fax: 972-37384051; E-mail: zalevsz@biu.ac.il processing circuits together with various nanophotonic devices while both are realized on the same silicon chip and both are designated towards bio sensing applications as part of the effort to realize a combined microelectronic/nanophotonic sensing and processing chip. The papers published in this special issue deal with the research activity being related to exactly this important interesting interface between the three scientific fields while presenting some recently obtained scientific advances and achievements in those highly evolving fields.

(C) Zeev Zalevsky; Licensee Bentham Open.

This is an open access article licensed under the terms of the Creative Commons Attribution Non-Commercial License (http://creativecommons.org/licenses/by$\mathrm{nc} / 3.0 /)$, which permits unrestricted, non-commercial use, distribution and reproduction in any medium, provided the work is properly cited. 